\title{
EL CONTROL CONSTITUCIONAL SOBRE LA IMPLEMENTACIÓN NORMATIVA DEL ACUERDO DE PAZ ENTRE EL GOBIERNO COLOMBIANO Y LAS FARC
}

\author{
CONSTITUTIONAL CONTROL ON THE NORMATIVE IMPLEMENTATION OF THE \\ PEACE AGREEMENT BETWEEN THE COLOMBIAN GOVERNMENT AND THE FARC
}

\begin{abstract}
Helton David Gutiérrez González
Abogado de la Universidad Libre, Seccional Barranquilla, Colombia, Especialista en derecho administrativo de la Universidad Externado de Colombia, Magister en derecho de la Universidad Sergio Arboleda, Bogotá, Doctor en derecho público de la Universidad Alfonso X El Sabio, Madrid, España, docente del área de derecho público de la Universidad Libre Seccional Bogotá, asesor y litigante en derecho administrativo y constitucional. E-mail: heltonguti@ hotmail.com
\end{abstract}

Convidado

Doi: $10.5585 /$ rdb.v18i7.779

RESUMEN: El papel de los tribunales constitucionales en razón a las dinámicas propias del derecho constitucional y de la ciencia jurídica en general nunca ha sido estático, por el contrario, muta con suma facilidad para encontrarse acorde a las exigencias que presentan los entornos jurídicos, en esta oportunidad, frente a una temática de relevancia jurídica para el ordenamiento jurídico colombiano, se observa la evolución de los esquemas de control de constitucionalidad que asume la Corte constitucional colombiana, aplicado a la implementación de las normas jurídicas que dan sustento jurídico al proceso de paz entre el gobierno nacional y las FARC-EP por la vía del procedimiento legislativo especial para la paz [PLEP], también conocido normas de tránsito rápido o citado por sus siglas en inglés, fast track.

Palabras claves: Control de constitucionalidad, Corte Constitucional, implementación, fast track, actos legislativos, sustitución de la Constitución.

\begin{abstract}
The constitutional tribunals' role according to the the own dinamics of the constitutional right and the legal science in general have never been static, it is the opposite way, it mutates with easiness to find itself agreeing with the demands of the legal environments, in this instance, facing the topic of legal relevance for the Colombian legal ordering. Being able to see the evolution of the constitutional control schematics under the watch of the Colombian constitutional court, applied on the implementation of legal rules giving legal support to the peace process between the national government and the FARC-EP using the special legal procedure for peace [PLEP], also known as FAST TRACK.

Keywords: Control of constitutionality, Constitutional Court, implementation, fast track, legislative acts, replacement of the Constitution.

SUMÁRIO: Introducción; 1. Antecedentes del proceso; 2. De los controles de constitucionalidad aplicables a las normas fast track; 2.1. Control sobre actos legislativos; 2.2. Control constitucional sobre leyes estatutarias, proyectos de ley y decretos con fuerza de ley; Conclusiones; Referencias.
\end{abstract}




\section{INTRODUCCIÓN}

La Corte Constitucional colombiana, como muchos tribunales constitucionales a nivel mundial posee rasgos muy propios de la cultura jurídica donde operan, en el caso colombiano, convergen muchas ideas u orientaciones externas en el joven sistema de control constitucional concentrado colombiano, donde los esquemas de control constitucional a cargo del máximo tribunal constitucional recoge como lo concluye Barrero $(2014$, p. 48) elementos de la judicial review norteamericana, el amparo mexicano, control concentrado austríaco, el previo francés, el helvético por vía de referendo y el colombo - venezolano por vía de acción.

Lo expuesto, aplicado a las realidades nacionales, ha convertido a la Corte constitucional colombiana en un actor principal en materias como el desarrollo y progresividad de los derechos fundamentales, los límites a los poderes de reforma constitucional, el equilibrio de los poderes públicos, el empoderamiento del recurso de amparo o acción de tutela, entre otros, haciendo que su papel preponderante en la cultura jurídica, política y económica, sea de los más resaltados a nivel continental.

Empero, las atribuciones desarrolladas por la Corte Constitucional -en adelante la Corteademás de admirables, por regla general se han realizado dentro de los parámetros competenciales que el constituyente primario le ha endilgado al tribunal constitucional colombiano, lo anterior pese a las controvertidas declaratorias de sustitución de la constitución, modulaciones temporales y en cuanto al contenido de sentencias de constitucionalidad (Charry, 2017), que demuestran entre otros reparos, una vis expansiva ${ }^{l}$ hermenéutica de las competencias normativas de la Corte de manera expresa al ejercerse la función de guarda en la supremacía e integridad constitucional e interprete autorizada de la constitución (Const., 1991, art. 241).

Ahora, el escenario presente que concita la atención sobre las funciones y atribuciones de la Corte Constitucional se refieren de forma expresa a las funciones de control constitucional de las normas de implementación del acuerdo de paz entre el gobierno de Colombia y las fuerzas armadas revolucionarias de Colombia [FARC-EP], las cuales son tramitadas mediante el mecanismo de tránsito rápido o también denominado fast track.

Este nuevo panorama competencial queda plasmado en el Acto Legislativo No. 01 de $2016^{2}$ que da origen al denominado procedimiento legislativo especial para la paz [PLEP], que refiere sobre las competencias de la Corte Constitucional en materia de control constitucional de las normas de implementación, lo siguiente:

(...) k) Los proyectos de ley y de acto legislativo tramitados mediante el Procedimiento Legislativo Especial para la Paz tendrán control automático y único de constitucionalidad, posterior a su entrada en vigencia. Las Leyes Estatuarias tendrán control previo, de conformidad con lo previsto en el artículo 153 de la Constitución. El control de constitucionalidad de los actos legislativos se hará solo por vicios de procedimiento en su formación. Los términos de esta revisión para leyes y actos legislativos se reducirán a la tercera parte de los del procedimiento ordinario y no podrán ser prorrogados.

Emana con claridad de la norma constitucional, lo siguiente: (i) el control que realiza la Corte, recae sobre normas jurídicas tales como, actos legislativos, proyectos de ley, leyes estatutarias y decretos con fuerza de ley, (ii) el control es automático para el caso de los actos legislativos, proyectos de ley y decretos con fuerza de ley, en tanto para las leyes estatutarias será

\footnotetext{
${ }^{1}$ La proposición vis expansiva ha sido utilizada por la Corte Constitucional para definir un margen amplio de desarrollo interpretativo judicial y legal, entre otros aspectos, para el control fiscal (Sentencia C-103 de 2015) y la descentralización administrativa (Sentencia C-035 de 2016).

2 "Por medio del cual se establecen instrumentos jurídicos para facilitar y asegurar la implementación y el desarrollo normativo del acuerdo final para la terminación del conflicto y la construcción de una paz estable y duradera".
}

Revista de Direito Brasileira | São Paulo, SP | v. 18 | n. 7 | p. 230 - 241 |Set./Dez. 2017 
previo y, (iii) el control es integral sobre las leyes estatutarias, proyectos de ley y decretos con fuerza de ley, en tanto que para los actos legislativos solo es procedente el control de la Corte sobre vicios de procedimiento en su formación.

No obstante, este diseño posee unas características adicionales que merecen ser revisadas, previa la contextualización y génesis histórica de estas funciones de control constitucional sobre normas de implementación jurídica de la paz o producto de la aplicación del procedimiento legislativo especial para la paz.

\section{ANTECEDENTES DEL PROCESO}

El gobierno de Colombia inició con las Fuerzas Armadas Revolucionarias de Colombia, diálogos exploratorios en La Habana Cuba entre los meses de febrero y agosto del año 2012, contando con la presencia de los gobiernos de Cuba, Noruega y Venezuela, allí se comprometieron a realizar diálogos directos e interrumpidos en una mesa de negociaciones a instalarse en Oslo, Noruega y desarrollarse en La Habana Cuba en los primeros 15 días del mes de octubre de 2012, lo anterior quedó consignado en el Acuerdo General para la Terminación del Conflicto y la Construcción de una Paz Estable y Duradera del 26 de agosto de 2012, quedando finalmente la mesa instalada el día 18 de octubre de 2012. (Acuerdo General para la terminación del conflicto y la construcción de una paz estable y duradera, 2012)

El desarrollo de las conversaciones, fueron realizadas de acuerdo al cronograma y a las temáticas planteadas, esto es, cobijando los seis puntos del acuerdo relativos a "Reforma Rural Integral", "Participación política: Apertura democrática para construir la paz", "Cese al Fuego y de Hostilidades Bilateral y Definitivo y la Dejación de las Armas", "Solución al Problema de las Drogas Ilícitas", "Víctimas" y "Mecanismos de implementación y verificación" que darían como resultado el logro de una paz estable y duradera. (Acuerdo General para la terminación del conflicto y la construcción de una paz estable y duradera, 2012a)

Finalmente, el 26 de septiembre del 2016, Gobierno y FARC-EP suscribieron en la ciudad de Cartagena, Colombia, el "Acuerdo Final Para la Terminación del Conflicto y la Construcción de una Paz Estable y Duradera", resultado de ello y como una decisión unilateral del gobierno colombiano, se procedió a someter a consulta del pueblo por vía del plebiscito, la política de paz.

Cabe precisar que muchos sectores de la opinión pública y de la academia coincidieron en sostener que la consulta al pueblo sobre el proceso de paz no era necesaria dadas las facultades del Presidente de la República para realizar este tipo de negociaciones (Charry, 2017), no obstante, como lo sostiene el mismo Charry (2017a), fue el camino más recomendable ante el desconocimiento de la opinión pública sobre el contenido y alcance del acuerdo, lo que consolidó la iniciativa de someterlo al plebiscito con el objetivo de dotar de mayor legitimidad lo acordado.

La anterior intención se materializó a través del Decreto 1391 del 30 de agosto de $2016^{3}$, vale clarificar, que este mecanismo de participación ciudadana sufrió una profunda reforma a través de la Ley Estatutaria 1806 del 24 de agosto de $2016^{4}$, que además de autorizar al Presidente de la República a convocar el "plebiscito para la paz" incorpora dos aspectos trascendentales a juicio del libelista, (i) la disminución del umbral de aprobación del 50\% al $13 \%$ de los votos del censo electoral y (ii) la decisión adoptada por el pueblo será vinculante, para los efectos del desarrollo legal y constitucional del acuerdo.

Lo anterior llevaba en principio el objetivo claro, cambiar la tendencia abstencionista del pueblo colombiano, constituyéndose en el mayor reto a vencer en esta justa electoral.

\footnotetext{
${ }^{3}$ Por el cual se convoca a un plebiscito y se dictan otras disposiciones.

${ }^{4}$ Por medio de la cual se regula el plebiscito para la refrendación del acuerdo final para la terminación del conflicto y la construcción de una paz estable y duradera.
} 
Así las cosas, la realización del plebiscito se pactó para el día 02 de octubre de 2016, donde los colombianos debían contestar la siguiente pregunta, "¿Apoya usted el Acuerdo Final para la Terminación del Conflicto y la Construcción de una Paz Estable y Duradera?», pregunta que los colombianos con una participación de 13.066.047 de personas de 34.899.945 habilitadas, lo que constituye el $37,43 \%$, decidieron decirle NO a la pregunta; la votación definitiva quedo por el NO, 6.431.376 de votos lo que equivale al 50,21\% y por el SI, 6.377 .482 de votos, lo que constituye el 49,78\% de los mismos. (Registraduría Nacional del Estado Civil, 2016)

Ante este "inesperado" resultado, el Gobierno Nacional junto con diversos sectores de la opinión pública y sociedad civil exploraron las posibilidades de ejecutar la voluntad de paz por medios distintos al apoyo popular directo, en ese interregno de tiempo, empieza a generar mayor protagonismo una decisión de la Corte Constitucional, conocida por medio del informe de ponencia de la hasta ese momento, debatida Sentencia C-699 de 2016 ${ }^{5}$, conocida con antelación por la opinión pública, alude especialmente al concepto de refrendación popular del acuerdo de paz; vale la pena mencionar, que esta temática no hacia parte de la agenda inicial sobre la cual se plantea la discusión de constitucionalidad, sobre el particular consideró:

En ese contexto preciso, la refrendación popular designa un (i) proceso, (ii) en el cual haya participación ciudadana directa, (iii) cuyos resultados deben ser respetados, interpretados y desarrollados de buena fe, en un escenario de búsqueda de mayores consensos, (iv)proceso que puede concluir en virtud de una expresión libre y deliberativa de una autoridad revestida de legitimidad democrática, (v) sin perjuicio de eventuales espacios posibles de participación ciudadana para la revisión específica de aspectos concretos ulteriores. Mientras los órganos políticos encargados de aplicar las previsiones del Acto Legislativo 1 de 2016 se mantengan dentro de esos límites, pueden definir si se ha cumplido la refrendación popular, que es condición para su entrada en vigencia. (Corte Constitucional, Sala Plena, C-699, 2016, Considerando 20).

Este nuevo panorama incorpora en la agenda de paz, una salida al entuerto que generó la decisión democrática-popular del plebiscito, y por medio de una decisión ultra petitum de la Corte Constitucional y por vía coyuntural, entiende que la refrendación popular del acuerdo se haría por vía indirecta y a través de una autoridad legítima democrática, que el caso concreto sería el Congreso de la República.

Esta decisión de la Corte adquiere relevancia para su estudio sobre las facultades atribuibles a los tribunales constitucionales en referencia especial a las normas no demandadas en el trámite del control de constitucionalidad contra actos legislativos, el cual en principio es rogado, además agrega la misma corporación judicial, sobre las causales que permiten realizar integración normativa a las proposiciones jurídicas no demandadas en juicios de control abstracto, no admiten interpretación analógica o extensiva. (Corte Constitucional, Sala Plena, C699, 2016a, Considerando 7 y 8).

Sin embargo, la Corte Constitucional de Colombia hace un estudio sobre el artículo $5^{\circ}$ del Acto Legislativo $1^{\circ}$ de 2016 y pese a que no se pronuncia en estricto sentido sobre su exequibilidad, ofrece una salida y, partiendo del carácter vinculante sólo para el Presidente de la República por ser una decisión de su exclusiva competencia (Charry, 2016), mas no obligatorio de la decisión del pueblo colombiano, entiende que el Congreso de la República es una autoridad legítima constituida democráticamente para implementar el acuerdo de paz con el gobierno nacional.

\footnotetext{
${ }^{5}$ Cabe resaltar que la sentencia fue dada a conocer por medio de comunicado de prensa No. 52 del 13 de diciembre
} de 2016 . 
La fórmula aplicada por el tribunal constitucional, por lo menos resulta en alguna medida incomprensible, en razón a la evidente imagen de desprestigio y desfavorabilidad que tiene el Congreso de la República de Colombia; el cual en reciente medición alcanza un porcentaje del $82 \%$ de imagen desfavorable (Periódico El Tiempo, 2017), por lo que resulta incoherente y contraproducente la legitimación que le otorga la Corte Constitucional al órgano legislativo colombiano, con la poca o nula credibilidad, confianza y favorabilidad que le tiene el pueblo colombiano.

Preliminarmente puede afirmarse que el rol en este proceso de implementación jurídica del acuerdo de paz, es preponderante por parte de la Corte Constitucional, y en suma sus decisiones han sido la columna vertebral para corregir los yerros en que incurrió el ejecutivo en su intención de aplicar unas medidas por completo impopulares e ilegítimas democráticamente, hoy jurídicamente legítimas a partir de las decisiones de la citada corporación judicial.

Finalmente, el acuerdo luego de unos ajustes con la convergencia de varios actores políticos y sociales, se firma en el Teatro Colón de Bogotá, el día 24 de noviembre de 2016, el cual fue refrendado por el Congreso de la República el 28 y 29 de noviembre de 2016 ratificada de forma posterior con la orientación de la Corte Constitucional a través de la pluricitada sentencia C-699 de $2016^{6}$.

Partiendo de lo ya expuesto, éstas no serían las únicas consideraciones que sobre el particular proferiría nuestra Corte Constitucional, en adelante las decisiones se concretarían en las facultades de control constitucional aplicables a las normas de implementación de la paz, dentro de las cuales encontramos en primera y única medida el acto legislativo para la paz condensado en la multicitada enmienda No. 01 de 2016.

\section{DE LOS CONTROLES DE CONSTITUCIONALIDAD APLICABLES A LAS NORMAS FAST TRACK}

Como se estudió a título enunciativo en la parte introductoria del presente documento, la Sentencia C-699 de 2016, constituiría el estudio de constitucionalidad de la enmienda realizada por el Congreso de la República para propiciar las condiciones de la implementación de las normas que daría vida al acuerdo de paz, así mismo, que establecería los parámetros de control para las normas de paz creadas a partir del mecanismo de transito rápido, los cuales variarían según el objeto jurídico sometido al control.

\subsection{Control sobre actos legislativos}

Una de las posibilidades polémicas existentes sobre las normas de implementación del proceso, sería sin duda la posibilidad de modificación constitucional, lo anterior porque justo antes de esta reforma nuestro sistema constitucional ya contaba con 40 reformas realizadas por vía de constituyente derivado y de las cuales 5 ya habían sido logrado se declaradas inexequible por parte de la Corte Constitucional resultado del no tan pacífico juicio de sustitución

\footnotetext{
${ }^{6}$ Se hace necesario recordar que la sentencia C-066 de 2016 fue dada a conocer mediante comunicado de prensa No. 52 del 13 de diciembre de 2016, el cual previo a ello el congreso había decidido implementar el acuerdo, asegurando que "El Senado adopta la decisión política de refrendar el Acuerdo Final para la Terminación del Conflicto y la Construcción de una Paz Estable y Duradera suscrito por el Gobierno Nacional y las Fuerzas Armadas Revolucionarias de Colombia -Ejército del Pueblo- el día 24 de Noviembre de 2016" y "Declarar que el Acuerdo Final para Terminación del Conflicto y la Construcción de una Paz Estable y Duradera firmado entre el Gobierno nacional y las FARC EP el 24 de Noviembre de 2016 fue el resultado de un proceso amplio y democrático cuya refrendación concluyó con las proposiciones aprobadas por las Cámaras legislativas el 29 y 30 de noviembre de 2016. Por lo tanto, el procedimiento especial legislativo previsto en el acto legislativo 01 de 2016 se encuentra vigente".
} 
constitucional $^{7}$, lo anterior, per se denota un sistema bastante flexible y proclive a la reforma de la constitución de acuerdo de forma coincidente a las variables políticas y económicas del país, incluso a la fecha y en virtud de esta posibilidad, el ordenamiento constitucional contabilizando actos legislativos por la vía de fast track, cuenta con 45 reformas a la carta política, esto con tan solo 26 años de existencia ${ }^{8}$ (Secretaría del Senado, 2017), en total estas reformas alcanzan a modificar 127 artículos de la constitución (Garcés, 2016), lo que equivale en promedio al 30\% del texto superior.

No obstante, la propuesta para la implementación de las normas de paz, implican la necesidad de reformar el texto, esta vez, con mayor agilidad para permitir su rápida incorporación al orden jurídico constitucional, los detalles de este propósito quedan condensados en el literal f) del artículo $1^{\circ}$ que consagra: "f) Los actos legislativos serán tramitados en una sola vuelta de cuatro debates. El tránsito del proyecto entre una y otra Cámara será de 8 días".

Ahora bien, en el mismo sentido el literal k) del mismo artículo, manifiesta cuáles serán los esquemas de control de constitucionalidad aplicables a las normas de implementación de paz, empero, la Corte realiza precisiones, que se justifican bajo el siguiente tenor:

(...), hay un control constitucional en el cual la Corte Constitucional debe hacer una revisión automática del procedimiento de formación de cada acto legislativo especial. En este escenario se da una nueva oportunidad para la participación ciudadana directa, a través de argumentos, que defienda o se oponga a la exequibilidad de la disposición constitucional.

En este estadio de la discusión, la Corte en primera medida ratifica y defiende no solamente su rol de garante del establecimiento constitucional, sino del mecanismo expedito de enmienda, explicando de forma adicional que es un mecanismo que opera para la consecución del fin altruista de la paz, dicho en otras palabras, la Corte avala el margen de flexibilidad constitucional, teniendo como fin último el logro de paz.

Vale la pena recalcar, que en el propósito de reforma constitucional se abre una posibilidad a criterio de la Corte para que se materialice la participación del ciudadano, en la medida que existe anteriormente, el instrumento de la coadyuvancia o impugnación de la reforma (Decreto, 2067, 1991, art. 7), legitimando aún más el discurso deliberativo, democrático y pluralista de la decisión a adoptar por parte de nuestro tribunal constitucional.

Ahora bien, la justificación que la Corte Constitucional ofrece sobre la existencia de este mecanismo rápido de enmienda constitucional, se condensa en los siguientes aspectos: (i) que el fin legítimo de las normas es el logro de la paz, (ii) el mecanismo de reforma no es definitivo sino especial, excepcional y transitorio, (iii) en el contexto de posconflicto, los procedimientos de expedición de actos legislativos es distinto al de las leyes por su nivel de dificultad; y, (iv) excepto el control sobre el Acto Legislativo, el mecanismo mantiene el nivel de resistencia al cambio de las normas constitucionales, no petrifica las cláusulas de reforma de la Constitución, no suprime, ni reduce la diversidad en los mecanismos de enmienda o sus formas de activación, ni tampoco equipara el poder constituyente a la competencia de revisión constitucional, por lo anterior, nuestro tribunal constitucional no encuentra un vicio de sustitución constitucional y otorga vía libre a las reformas a precaver. La ratio de esta decisión se condensaría en los siguientes apartes:

\footnotetext{
${ }^{7}$ Sobre el particular se pueden revisar, Sentencias C-373 de 2016, C-1056 de 2012, C-249 de 2012, C-588 de 2009 y C-1040 de 2005.

${ }^{8}$ La Constitución Política de Colombia de 1991 fue promulgada por medio de la Gaceta Constitucional No. 116 de 20 de julio de 1991
} 
Estas variaciones en modo alguno remplazan por uno distinto el principio de resistencia constitucional relativa, variable, diversa y funcionalmente diferenciada. Por el contrario, se ajustan al marco constitucional prexistente. De manera que no encuentra la Corte un vicio de competencia por sustitución. (Corte Constitucional, Sala Plena, C-699, 2016b, Considerando 54)

En virtud de la anterior decisión, hasta la fecha se han proferido 4 actos legislativos ${ }^{9}$, se esperan 4 más, (Charry, 2017) los cuales a su vez han desatado discusiones y retos de alta relevancia constitucional que vale comentar, pero sin duda y en concentración del discurso del alcance control de constitucionalidad, se hará mención en el siguiente sentido.

Inicialmente, lo primero sería fijar el alcance de las tensiones constitucionales que han de regir los juicios a aplicar por parte de la Corte, así, (i) se ofrece garantía que las normas de implementación en efecto desarrollen el Acuerdo Final, (ii) además se trata de evitar el uso indebido e inconveniente de las normas fast track limitándolo a aprobar medidas que se encuentren realmente vinculadas a los contenidos del Acuerdo y (iii) se garantice que la implementación normativa cumpla las obligaciones pactadas por las partes.

Por último y como eje fundamental del control, (iv) se procura la salvaguarda en el sentido que el Acuerdo y las normas que lo desarrollen, no impliquen un desconocimiento de la Constitución Política- (DeJustica et al, 2017)

Un caso concreto, del esquema de control propuesto lo materializa la Sentencia C-630 de 2017, contenido en el comunicado del No. 51 del 11 de octubre de 2017, donde se estudia el acto legislativo No. 02 de $2017^{10}$, en dicha sentencia se explica:

En relación con los parámetros especiales de competencia que surgen de la aplicación del Acto Legislativo 1 de 2016, la Corte encontró que el Acto Legislativo 02 de 2017 cumplió con los criterios de: (i) conexidad material; (ii) conexidad teleológico o de finalidad; (iii) temporalidad; y (iv) de habilitación competencial, en la medida que el mismo responde a los propósitos de facilitar y asegurar la implementación del Acuerdo Final, se expidió dentro del periodo de vigencia del Procedimiento Legislativo Especial para la Paz y fue promovido a iniciativa exclusiva del Gobierno Nacional.

Sin embargo, a juicio respetuoso del suscrito, este no fue un asunto de trascendencia a estudiar en el rol de la Corte Constitucional, lo que ofrece un parámetro relevante dentro de las atribuciones de la Corte para el estudio de la reforma, es que el control que realiza en el caso concreto, antes de circunscribirlo a vicios competenciales, realiza una verificación hermenéutica de los artículos del acto reformatorio, justificado en la indeterminación del mismo y con miras a evitar la configuración del fenómeno de la sustitución constitucional.

En este ejercicio, de forma respetuosa se considera que la Corte no solo se limita a la verificación de vicios competenciales, sino que aparejado a ello, otorga a través de un estudio interpretativo de la disposición, los insumos semánticos para la solución y concreción del juicio

\footnotetext{
${ }^{9}$ Acto legislativo 1 de 2017. Por medio del cual se crea un título de disposiciones transitorias de la Constitución para la terminación del conflicto armado y la construcción de una paz estable y duradera y se dictan otras disposiciones. Acto legislativo 2 de 2017. Por medio del cual se adiciona un artículo transitorio a la Constitución con el propósito de dar estabilidad y seguridad jurídica al acuerdo final para la terminación del conflicto y la construcción de una Paz Estable y Duradera.

Acto legislativo 3 de 2017. Por medio del cual se regula parcialmente el componente de reincorporación política del Acuerdo Final para la Terminación del Conflicto y la Construcción de una Paz Estable y Duradera.

Acto legislativo 4 de 2017. Por el cual se adiciona el artículo 361 de la Constitución Política.

${ }^{10}$ Por medio del cual se adiciona un artículo transitorio a la Constitución con el propósito de dar estabilidad y seguridad jurídica al acuerdo final para la terminación del conflicto y la construcción de una paz estable y duradera
}

Revista de Direito Brasileira | São Paulo, SP | v. 18 | n. 7 | p. 230 - 241 | Set./Dez. 2017 
formal de la enmienda, lo que podría asumirse eventualmente ${ }^{11}$ como una forma de extender impropiamente la facultad de control de la Corte o constituir en sentido amplio un reemplazo a la voluntad del constituyente derivado de una interpretación ex normativa.

Finalmente, algunas críticas se realizan a la Corte Constitucional sobre los límites de su control, en esta ocasión al verificar normas como los literales h) y j) del artículo $1^{\circ}$ del Acto Legislativo 01 del 2016, los cuales son declarados inexequibles mediante Sentencia C-332 del 17 de mayo de 2017, a pesar de haber declarado con anterioridad su constitucionalidad en la Sentencia C-699 del 2016, lo que denota cierta incoherencia y desarticulación de sus decisiones. (Charry, 2017a).

\subsection{Control constitucional sobre leyes estatutarias, proyectos de ley y decretos con fuerza de ley}

Ahora bien, en consonancia con la propuesta descriptiva del presente documento, el control de constitucionalidad aplicado a las leyes estatutarias, proyectos de ley y decretos ley, es totalmente distinto al aplicado a los actos legislativos, donde su cualidad principal la constituye, ser integral, sobre el particular la Corte indica en especial mención a los decretos que: "Por una parte, los decretos ley que se profieran a causa del Acto Legislativo 1 de 2016 tienen control constitucional automático, posterior e integral".

Como ya se indicó, las limitaciones sobre el control aplicable a los actos legislativos, es diametralmente distinto al aplicado a las normas con fuerza material de ley, sobre éstos su control y estudio se centrará en determinar (i) si ellos cumplen su finalidad, esto es, facilitar o asegurar el desarrollo normativo del acuerdo de paz, (ii) que estos decretos sean conexos al acuerdo, (iii) excepcionales, y (iv) conformes a la constitución. Sobre el particular, se precisa:

En desarrollo de este control, la Corte deberá verificar que los decretos con fuerza de ley cumplan la finalidad para la cual se confieren las facultades, a saber, facilitar o asegurar el desarrollo normativo del acuerdo final; que tengan entonces una conexidad objetiva, estricta y suficiente con el referido acuerdo; que se den en circunstancias excepcionales, pues las facultades son precisamente extraordinarias, lo cual supone que sea necesario usarlas en vez de acudir al trámite legislativo ante el Congreso; y que respeten en general el ordenamiento constitucional. Por su parte, el Congreso preserva las competencias de control político y jurisdiccional sobre el Gobierno y el Presidente de la República (CP arts. 114, 174 y 178). (Corte Constitucional, Sala Plena, C-699, 2016c, Considerando 66)

En el panorama antes descrito, basta distinguir los aspectos temporales que afectan las normas jurídicas sometidas al control de las decisiones de la Corte Constitucional, por una parte, los controles a precaver sobre los proyectos de ley y decretos con fuerza de ley son automáticos y posteriores, esto es, entran en vigencia las disposiciones y la decisión sobre su exequibilidad es posterior.

Distinto es el panorama aplicable a las leyes estatutarias, que pese a tener un control integral, este es previo, traduciendo lo anterior, que las normas quedan supeditadas a la decisión de la Corte Constitucional para su entrada en vigencia, por lo que la disposición será una con la decisión de la Corte, constituyendo una especie de decisión comprendida entre la iniciativa ejecutiva, la deliberación parlamentaria y el control judicial constitucional.

\footnotetext{
${ }^{11}$ La palabra eventual se utiliza dado que, a la fecha de depósito del presente documento, no se conoce el texto completo de la sentencia bajo estudio.
} 
Como resultado del diseño anterior, se han proferido cantidad de decisiones por parte de la Corte Constitucional, resultado del esquema de control aplicable al paquete normativo que como lo sostiene Charry (2017) a octubre del presente año, es de 3 leyes, 35 decretos-leyes, 40 decretos reglamentarios y 2 leyes estatutarias en trámite, traduce lo anterior que el trabajo de la Corte Constitucional se ha visto engrandecido en volumen y ha forzado a este tribunal ha responder a las exigencias temporales y a la coyuntura política de nuestro país que espera con miras a la elección del nuevo presidente del país, dejar implementado por vía normativa y judicial el acuerdo suscrito entre el estado colombiano y el hoy partido político de Fuerza Alternativa Revolucionaria del Común [FARC] (Consejo Nacional Electoral [CNE], 2017).

Finalmente, se observa serías tensiones al interior de la Corte Constitucional al tener que decidir sobre la constitucionalidad de asuntos neurálgicos del acuerdo, tales como la Justicia Especial para la Paz $[\mathrm{JEP}]^{12}$, ponencia que resulta bastante diciente en materia de extensión del control de la Corte (Revista Semana, 2017) y por su parte ha sido la misma corporación la cual avaló la fórmula de blindaje jurídico de los acuerdos de paz, marcando su eficacia jurídica como margen hermenéutico de las normas jurídicas nacionales y que su vocación de permanencia sería hasta tres períodos presidenciales (Corte Constitucional, Sala Plena, C-630, 2017).

Como conclusión de los controles de constitucionalidad aplicados por la Corte, empieza a ser más frecuente la implementación de la idea del doble juicio de competencia o doblemente ponderado de las normas de justicia transicional (Uprimny, 2017), sobre todo en lo que refiere actos legislativos.

Una idea de esta tendencia es recogida por la Corte Constitucional cuando considera que:

(...) el análisis de las normas que tienen relación con los instrumentos de la justicia transicional exige tener en cuenta que cuando la exequibilidad de una medida dependa del resultado de una ponderación entre los principios constitucionales en que ella se fundamente, por una parte, y los principios constitucionales que ella limite, por otra, el principio constitucional y derecho fundamental a la paz suma su peso a aquellos.

Lo anterior permite inferir, que el derecho a la paz tiene un ingrediente de peso adicional que resulta favorable en la ponderación de derechos que se encuentran en conflicto en la aplicación de instrumentos de justicia transicional, con estricto carácter temporal, por ende, resulta justificado en algunos casos la flexibilización de la intensidad del control de constitucionalidad en la medida que en este contexto el legislador transicional dispone de un margen de acción más amplio que en tiempos de normalidad institucional (Corte Constitucional, Sala Plena, C-554, 2017).

\section{CONCLUSIONES}

Como se señaló al inicio de la presente reflexión, el rol de la Corte Constitucional ha sido fundamental en Colombia en el denominado proceso de posconflicto, en apreciación personal, la corte más allá más de fungir de garante de la integridad y supremacía constitucional

\footnotetext{
${ }^{12}$ A la fecha de depósito del presente documento se conoció por parte de la prensa que la Corte Constitucional había declarado al exequibilidad del Acto Legislativo 01 de 2017 sobre Justicia Especial para la Paz, no obstante se lee con facilidad que el Alto Tribunal hizo serios reparos al proyecto de acto legislativo ratificación aún más su papel de protagonista en la escena constitucional colombiana, aparte del comunicado sostiene: "El acto legislativo cumplió en general con los requisitos de la ley (...) Esta norma va en una transición hacia la paz, por lo que se exigía ver el acto legislativo a la luz de construir un sistema de verdad, justicia, reparación y no repetición”, dijo el magistrado Luis Guillermo Guerrero, presidente de la Corte. http://www.eltiempo.com/justicia/cortes/corte-constitucional-avalo-lajusticia-para-la-paz-jep-151378
}

Revista de Direito Brasileira | São Paulo, SP | v. 18 | n. 7 | p. 230 - 241 | Set./Dez. 2017 
en un sentido clásico en lo que corresponde a la revisión en la implementación de las normas jurídicas, ha sido fundamental para superar los obstáculos e imperfecciones del proceso de implementación por parte del gobierno nacional.

La Corte Constitucional asume la función co-protagónica en el proceso de paz entre el gobierno nacional y las FARC en momentos de dificultad institucional y en periodo de interinidad de sus miembros, lo que en principio hacia dudar de la legitimación de las decisiones de este alto tribunal.

La Corte Constitucional mantiene los clásicos esquemas de control constitucional, siendo para el caso de las normas de implementación de la paz mediante el mecanismo fast track, que varían según el objeto jurídico sometido al control.

La Corte Constitucional dada su corta pero fructífera experiencia y legitimidad institucional en Colombia, se ha situado en el filtro institucional-judicial para que las normas que integran el basto universo jurídico colombiano, más concretamente en las normas de implementación de paz vayan acorde al ordenamiento constitucional interno.

No obstante, las conclusiones antes expresadas, aún quedan muchas dudas que restan resolver para la comprensión constitucional del fenómeno interno colombiano hoy entendido como posconflicto.

Vrg., ¿qué juez revisará o resolverá la eventual inconvencionalidad de ciertas disposiciones normativas del acuerdo, tales como la violación al principio democrático?

¿Es la Corte Constitucional la última palabra en la implementación del acuerdo de paz?, esto es, ¿el consenso generalizado de aceptación sobre este tribunal, se encuentra exento de cualquier cuestionamiento político o jurídico?

¿Puede la Corte Constitucional ejercer un idóneo control de constitucionalidad cuando se le endilgaron este tipo de responsabilidades a través del Acto Legislativo 01 de 2016, cuando en sí, la constitución ya no era una norma jurídica en los términos en que la ideó el constituyente de 1991 ?

Los anteriores cuestionamientos no llevan otra intención que entender el papel presente y futuro de nuestro tribunal constitucional y los retos que se afrontan en nuestro país, en un tema de trascendencia histórica y jurídica como es la Paz.

\section{REFERENCIAS}

\section{Doctrina}

Barrero, J.A. (2014). Jurisprudencia constitucional. Bogotá: Legis.

\section{Legislación}

\section{Actos Legislativos}

Congreso de Colombia. (7 de julio de 2016). Por medio del cual se establecen instrumentos jurídicos para facilitar y asegurar la implementación y el desarrollo normativo del acuerdo final para la terminación del conflicto y la construcción de una paz estable y duradera. [Acto Legislativo No. 1 de 2016]. DO: 49.927.

Congreso de Colombia. (11 de mayo de 2017). Por medio del cual se adiciona un artículo transitorio a la constitución con el propósito de dar estabilidad y seguridad jurídica al acuerdo final para la terminación del conflicto y la construcción de una paz estable y duradera. [Acto Legislativo No. 2 de 2017]. DO: 50.230. 


\section{Leyes Nacionales}

Congreso de Colombia. (24 de agosto de 2016). Por medio de la cual se regula el plebiscito para la refrendación del acuerdo final para la terminación del conflicto y la construcción de una paz estable y duradera [Ley 1806 de 2016]. DO: 49.975.

\section{Decretos nacionales}

Presidencia de la República. (30 de agosto de 2016). por el cual se convoca a un plebiscito y se dictan otras disposiciones. [Decreto 1391 de 2016]. DO: 49.981.

Presidencia de la República. (4 de septiembre de 1991). Por el cual se dicta el régimen procedimental de los juicios y actuaciones que deban surtirse ante la Corte Constitucional. [Decreto 2067 de 1991]. DO: 40.012.

\section{Jurisprudencia}

Corte Constitucional, Sala Plena. (11 de octubre de 2017) Sentencia C-630. [MP Luis Guillermo Guerrero Pérez y Antonio José Lizarazo Ocampo]

Corte Constitucional, Sala Plena. (17 de mayo de 2017) Sentencia C-332. [MP Antonio José Lizarazo Ocampo]

Corte Constitucional, Sala Plena. (30 de agosto de 2017) Sentencia C-554. [MP Carlos Bernal Pulido]

Corte Constitucional, Sala Plena. (13 de diciembre de 2016) Sentencia C-699. [MP María Victoria Calle Correa]

\section{Revistas y artículo de prensa}

Congreso de Colombia. (24 de octubre de 2017) Recuperado de: http://www.secretariasenado.gov.co/index.php/leyes-y-antecedentes/constitucion-y-sus-reformas

Consejo Nacional Electoral. (31 de octubre de 2017). Comunicado de prensa 143. Recuperado de:

DE_PRENSA_143_31_OCTUBRE_DE_2017.news

http://www.cne.gov.co/cne/COMUNICADO-

Charry, J.M. (11 de octubre de 2017). Plebiscito: un años después. Ámbito jurídico. Recuperado de: $\quad$ https://www.ambitojuridico.com/BancoConocimiento/Constitucional-y-DerechosHumanos/plebiscito-un-ano-despues

Charry, J.M. (08 de junio de 2017). Adiós a la Constitución. Ámbito jurídico. Recuperado de: https://www.ambitojuridico.com/BancoConocimiento/Administracion-Publica/adios-a-laconstitucion 8 de junio de 2017

Charry, J.M. (01 de septiembre de 2016). Reglas constitucionales para el plebiscito. Ámbito jurídico. Recuperado de: https://www.ambitojuridico.com/BancoConocimiento/Constitucional-yDerechos-Humanos/reglas-constitucionales-para-el-plebiscito 
DeJusticia. (15 de marzo de 2017). Comunicado sobre transparencia y publicidad de decretosleyes y gestión de procesos de la corte constitucional, en la implementación normativa vía fasttrack. Recuperado de: https:/www.dejusticia.org/wpcontent/uploads/2017/04/fi_name_recurso_929.pdf

El Tiempo. (01 de noviembre de 2017). La imagen desfavorable de los partidos políticos llegó al $89 \%$ Recuperado de: http://www.eltiempo.com/politica/partidos-politicos/imagen-desfavorablede-los-partidos-politcos-segun-resultados-de-la-encuesta-bimestral-de-gallup-147286

Garcés, M.T. (01 de julio de 2016). Las 41 reformas a la Constitución. El espectador. https://www.elespectador.com/noticias/politica/41-reformas-constitucion-articulo-640997

General. (04 de octubre de 2017). ¿Qué tipo de control de constitucionalidad se aplica a la normativa transicional? Ámbito jurídico. Recuperado de: https://www.ambitojuridico.com/BancoConocimiento/Constitucional-y-Derechos-Humanos/quetipo-de-control-de-constitucionalidad-se-aplica-a-la-normativa-transicional

Gobierno de Colombia y FARC. (26 de agosto de 2012). Acuerdo General para la terminación del conflicto y la construcción de una paz estable y duradera. Recuperado de: http://www.altocomisionadoparalapaz.gov.co/procesos-y-conversaciones/acuerdogeneral/Documentos\%20compartidos/Acuerdo_General_para_la_terminacion_del_conflicto.pdf

Mesa de conversaciones. (24 de noviembre de 2016). ACUERDO FINAL PARA LA TERMINACIÓN DEL CONFLICTO Y LA CONSTRUCCIÓN DE UNA PAZ ESTABLE Y DURADERA. Recuperado de: http://www.altocomisionadoparalapaz.gov.co/mesadeconversaciones/index.html

Registraduría. (02 de octubre de 2016). Plebiscito 2 de octubre de 2016. Recuperado de: http://plebiscito.registraduria.gov.co/99PL/DPLZZZZZZZZZZZZZZZZZ_L1.htm

Semana. (04 de noviembre de 2017). La JEP 'Frankenstein'. Recuperado de: http://www.semana.com/nacion/articulo/jep-corte-constitucional-propone-aprobar-el-sistema-dejusticia-transicional/546059

Uprinmy, R. ( 04 de julio de 2017). Resumen intervención de Rodrigo Uprimny Yepes. Dejusticia. Recuperado de: https://www.dejusticia.org/wp-content/uploads/2017/07/AudienciaP\%C3\%BAblica-Intervenci\%C3\%B3n-RUY.pdf 